\title{
Análise multicritério para avaliar a qualidade de sistemas de abastecimento de água e esgotamento sanitário nos municípios do Curimataú Oriental Paraibano, Brasil
}

\section{Multicriteria analysis to evaluate the quality of water supply and sewage systems in the municipalities of Oriental Curimataú of Paraíba, Brazil.}

\author{
Data de entrada: \\ 19/09/2019 \\ Data de aprovação: \\ $02 / 07 / 2020$
}

Cinthia Maria de Abreu Claudino ${ }^{1 * *}$ | Beatriz de Almeida Gomes ${ }^{1}$ | Igor Souza Ogata ${ }^{2}$ | Thiago de Sá Sena ${ }^{3}$

\section{ORCID ID}

Claudino CM (D) https://orcid.org/0000-0003-4233-6082

Gomes BA (iD) https://orcid.org/0000-0003-4372-2719
Ogata IS (i) https://orcid.org/0000-0002-9770-3890

Sena TS (DD https://orcid.org/0000-0003-1593-3439

\section{Resumo}

Devido ao panorama deficiente de abastecimento de água e esgotamento sanitário das cidades de pequeno porte, o trabalho aplicou modelo de apoio a tomada de decisão multicriterial para avaliar os sistemas em municípios da Microrregião do Curimataú Oriental Paraibano. Para tanto, foram utilizados como critérios indicadores do Sistema Nacional de Informações sobre Saneamento, aplicados no método ELECTRE II. O resultado classificou os municípios quanto às categorias Operacional, Econômico-Financeiro e Administrativo e de Qualidade. Ao analisar as três categorias em conjunto, o município de Solânea apresentou melhor desempenho, enquanto Cacimba de Dentro teve o pior. Esse resultado foi alcançado principalmente pelo desempenho associado à cobertura do abastecimento de água e endividamento dos usuários. Assim, a pesquisa orienta a tomada de decisão para ações prioritárias no local e categorias adequadas, sendo até mesmo possível ser aplicada em outras regiões brasileiras.

Palavras-chave: Método ELECTRE II. Municípios de pequeno porte. Sistema de informação sobre saneamento.

\section{Abstract}

Owing to the scanty water supply and sewage systems of small towns, this work applied a multicriteria decision support model to evaluate these systems in municipalities on Oriental Curimataú Microregion of Paraíba, Brazil. Therefore, were used as criteria, the indicators of Brazilian Sanitation Information System, applied on ELECTRE II Method. The outcome ranked these municipalities in relation to Operational, Economic-Financial and Administrative and Quality categories. When it analyzed these categories together, the Solanea town was the best situation, whereas Cacimba de Dentro town was the worst. This situation was achieved because of performance associated to water coverage and user's indebtedness. Thus, this research guides the decision-making for priority action at level of appropriated place and categories, being even possible carry out on another Brazilian places.

Keywords: ELECTRE II Method. Small-sized municipalities. Sanitation information system.

\footnotetext{
1 Universidade Federal da Paraíba - João Pessoa - Paraíba - Brasil.

${ }^{2}$ Universidade Estadual da Paraíba - Araruna - Paraíba - Brasil.

${ }^{3}$ Universidade Federal de Campina Grande - Campina Grande - Paraíba - Brasil.

* Autora correspondente: cinthiamariaacagmail.com.
} 


\section{INTRODUÇÃO}

Para garantir o bem-estar social é necessário a formação de um ambiente saudável (ATAÍDE; BORJA, 2017; DUTRA et al., 2018). No caso do ambiente urbano brasileiro, o conceito de ambiente saudável é abordado pela Lei No 10.257/2001 o Estatuto das Cidades -, que garante o direito à terra urbana, moradia, saneamento ambiental, infraestrutura urbana, transporte e serviços públicos, trabalho e lazer, para as presentes e futuras gerações. Sendo assim, um ambiente adequado está diretamente associado à disponibilidade de serviços de saneamento básico.

Portanto, o saneamento básico possui grande importância na salubridade de ambientes urbanos, pois os aspectos sanitários e ambientais estão estreitamente relacionados ao contexto social, econômico, jurídico e institucional (GRISOTTO et al., 2012; PAIVA; SOUZA, 2018). No Brasil, por exemplo, o saneamento básico é um direito assegurado pela Constituição e regulamentado pela Lei № $11.445 / 2007$, que dentre outras diretrizes exige a obtenção da universalização dos serviços.

A busca pela universalização do saneamento básico já movimentou, em várias fases da história do país, diversos planos e investimentos (COSTA; PINHEIRO, 2018; TELES, 2019; TOMÉ, 2018). No entanto, de acordo com a Confederação Nacional das Indústrias (CNI) (2017), com o aporte atual de recursos, a universalização só será atingida em 2054.

Vários motivos e aspectos podem ser relacionados à dificuldade do Brasil em alcançar a universalização. Dentre estes, o mais incontestável é a desigualdade social, na qual, predominantemente, a população sem esses serviços está localizada em municípios de pequeno porte ou baixo poder econômico, periferias e zonas rurais isoladas (IPEA, 2010; MENDES; BARCELLOS, 2018; NAHAS et al., 2019). Essa inferência é re- forçada pelos dados do último censo, realizado pelo Instituto Brasileiro de Geografia e Estatística (IBGE) (2011), que expõe que os municípios de pequeno porte são os que possuem as piores condições de infraestrutura urbanística básica, incluindo a de saneamento.

Quando se analisa o panorama dos serviços de abastecimento de água e de esgotamento sanitário, que são as condicionantes mais abrangentes do saneamento básico, é possível verificar o anteriormente exposto. A respeito do abastecimento de água, apenas 33 dos 5.564 municípios não dispunham de rede geral, sendo que $63,3 \%$ estão na Região Nordeste e 33,3\% no Estado da Paraíba, um dos estados mais pobres da federação. Quanto ao esgotamento sanitário, os cinco piores estados brasileiros em cobertura de rede coletora estão nas Regiões Norte e Nordeste, que não tratam nem $20 \%$ dos efluentes coletados (IBGE, 2010).

Diante dessa realidade, é inegável a importância de avaliar adequadamente essa condição em busca de investir eficientemente. Para tanto, existem inúmeras opções de ferramentas (ALENCAR FILHO; ABREU, 2005; DANTAS et al., 2012; MOTA et al., 2015; NIRAZAWA;

OLIVEIRA, 2018; PINHEIRO et al.; 2017; QUEIROZ et al., 2018), e uma das principais técnicas é o controle ou auditoria gerencial baseada em indicadores de gestão (ALEGRE et al., 2006), pois os indicadores representam uma visão abrangente de um sistema por meio de uma abordagem limitada (CECCONI et al., 2007).

Em atenção a essa ferramenta, o Sistema Nacional de Informações sobre Saneamento (SNIS) foi criado e se transformou no maior e mais importante banco de dados do setor de saneamento brasileiro, devido à grande abrangência dos indicadores disponíveis (CARNEIRO et al.; 2018), que vem contribuindo para vários estudos no planejamento e na execução de ações eficientes 
em saneamento (CARVALHO et al., 2019; COSTA; PINHEIRO, 2018; NIRAZAWA; OLIVEIRA, 2018; SOUSA et al.; 2018; TOMÉ, 2018).

Devido à multiplicidade de indicadores fornecidos pelo SNIS, sua análise se torna complexa. Portanto, é interessante o uso de análise multicriterial, que se destaca pela capacidade de avaliar situações por meio de vários critérios e indicando a mais favorável (LONGARAY et al., 2016).

Dentre os métodos multicritério, o Elimination et Choix Traduisant la Réalité (ELECTRE) se destaca devido à vasta aplicação em todas as áreas do conhecimento (ISHIZAKA; NEMERY, 2013), em que, segundo Araújo e Amaral (2016), houve um aumento de $80 \%$ de publicações com uso do método entre 2012 e 2015 . O método ELECTRE é uma ferramenta utilizada em situações problemáticas em que se busca analisar a superação entre as alternativas, sendo assim classificado como um método multicriterial de sobreclassificação (ALMEIDA, 2013), que quando se pretende ordenar alternativas da melhor para a pior, a versão ELECTRE II é a mais aplicada (GOVINDAN; JEPSEN, 2014).

\section{OBJETIVO}

Visto o cenário relatado, o trabalho aplicou o método ELECTRE II para apoio à tomada de decisão multicriterial em indicadores do SNIS, a fim de avaliar a qualidade dos sistemas de abastecimento de água e esgotamento sanitário dos municípios da Microrregião do Curimataú Oriental Paraibano.

\section{METODOLOGIA}

\subsection{Características científicas da pesquisa}

A pesquisa teve enfoque qualiquantitativo, pois nas etapas de seleção e normalização dos critérios foi trabalhada a relação dos indicadores do SNIS com a condição do saneamento do local estudado, enquanto nos métodos matemáticos da normalização e ponderação dos critérios traduziu-se essa relação em números. Quanto aos fins da pesquisa, esta foi metodológica e prática, uma vez que propõe uma metodologia para análise de sistemas de abastecimento de água e esgotamento sanitário ao mesmo tempo em que aplica a metodologia em uma área real.

No caso do modelo de apoio à tomada de decisão multicritério, este possui enfoque prescritivo e construtivo, dado que os elementos de decisão foram coletados com base nos indicadores do SNIS e a ponderação levou em consideração a preferência de decisores. Em relação ao número de alternativas, o método foi discreto, por haver um número limitado de alternativas. Outro aspecto é a sobreclassificação do método, por ter sido selecionado o método ELECTRE II. As características científicas da pesquisa estão resumidas na Tabela 1.

Tabela 1 - Síntese das características científicas da pesquisa

\begin{tabular}{|c|c|c|c|}
\hline \multicolumn{2}{|c|}{ Método científico } & \multicolumn{2}{c}{ Modelo de apoio à tomada de decisão } \\
\hline Enfoque da pesquisa & Qualitativo e quantitativo & Enfoque & Prescritivo e construtivo \\
\hline Fins da pesquisa & Metodológica e prática & Discreto \\
\hline Instrumentos & $\begin{array}{c}\text { Pesquisa em literatura, dados do SNIS } \\
\text { e questionários }\end{array}$ & Classe & Método de sobreclassificação \\
\hline
\end{tabular}

\subsection{Local da pesquisa}

O local de desenvolvimento da pesquisa foi a Microrregião do Curimataú Oriental do estado brasileiro da
Paraíba, espacializada na Fig. 1, que também apresenta a área e a população estimadas para o ano de 2017 dos municípios que a constitui (IBGE, 2018). 


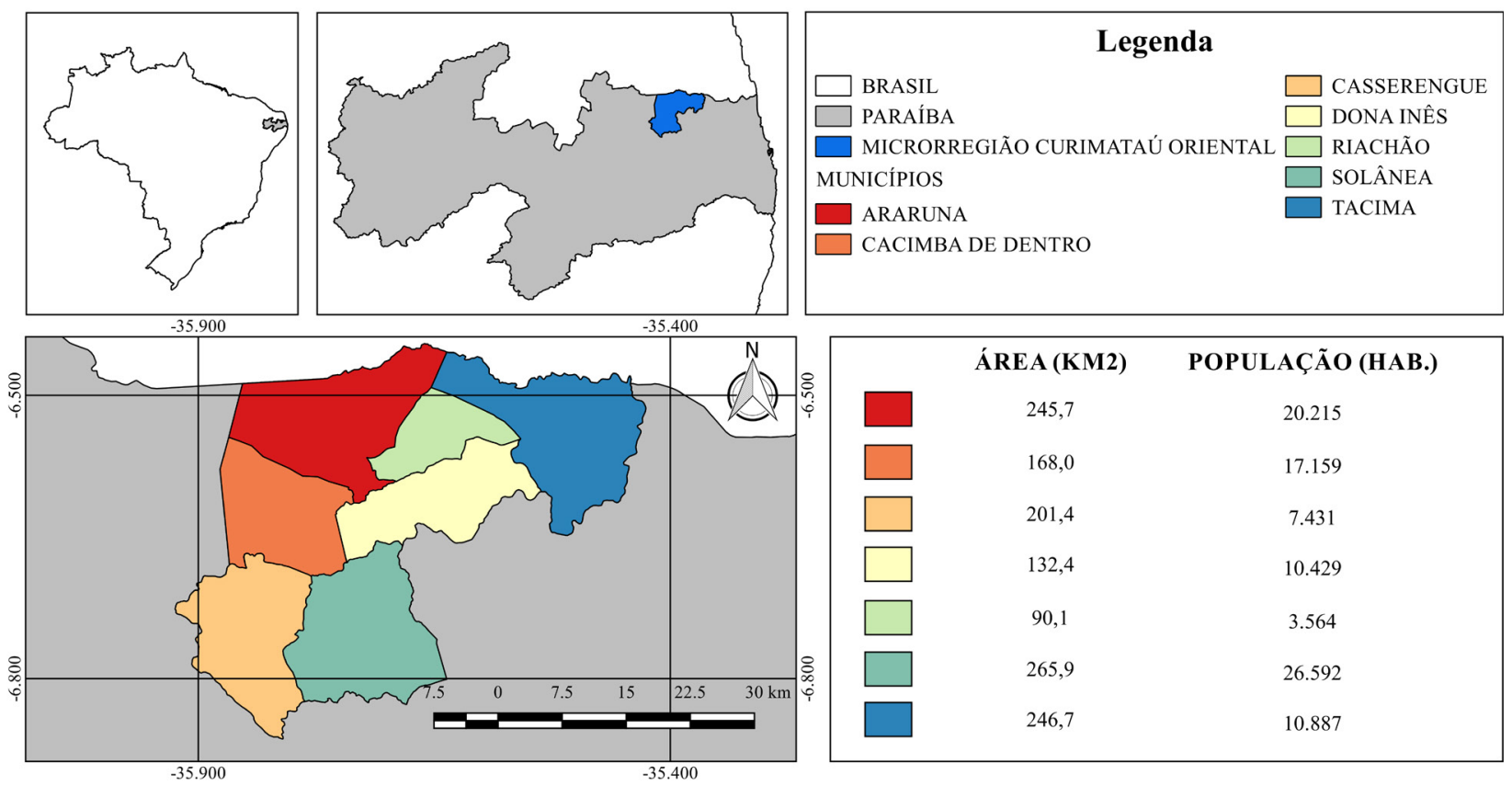

Figura 1 - Municípios da Microrregião do Curimataú Oriental paraibano (área e população) Fonte: Elaborada pelos autores.

A microrregião possui uma área total de 1.307,4 $\mathrm{km}^{2}$, abrigando 96.383 habitantes; seus sete municípios possuem condição socioeconômica e de infraestrutura de saneamento homogêneas, caracterizadas por serem de pequeno porte e com problemas crônicos de abastecimento de água e esgotamento sanitário, tornando mais difícil a tomada de decisão. Assim, essa área foi selecionada para verificar a aplicabilidade do método em condições muito semelhantes.

\subsection{Seleção dos critérios e coleta dos dados}

Para aplicação do método ELECTRE II, é necessário definir critérios que representem os sistemas de abastecimento de água e esgotamento sanitário. Assim, foi feito um Check List dos índices disponíveis no SNIS, e em seguida foram eliminados aqueles que representam informações duplicadas ou indisponíveis, de maneira que 14 indicadores foram selecionados (Tabela 2) para representar os critérios do método multicriterial.

Esses critérios foram organizados em três categorias, denominadas de Operacional, EconômicoFinanceiro e Administrativo e Qualitativo. Cada critério possui uma referência direta no SNIS, exceto o critério operacional $\mathrm{O3}$, os econômico-financeiro e administrativo E3 e E4 e os qualitativos Q1 e Q2, que necessitaram ser calculados por meio de associação dos indicadores do SNIS. A forma de cálculo dos critérios supracitados está representada na Tabela 2.

Definidos os critérios, os dados foram coletados no banco de dados do SNIS, para o ano de 2013, por ser o ano com informações completas para todos os sete municípios. 
Tabela 2 - Índices do SNIS selecionados como critérios

\begin{tabular}{|c|c|c|c|c|}
\hline Categoria & Critério & Descrição & Referência SNIS & Unidade \\
\hline \multirow{6}{*}{ Operacional } & 01 & $\begin{array}{l}\text { Índice de atendimento total } \\
\text { de água }\end{array}$ & IN055 & $\%$ \\
\hline & $\mathrm{O} 2$ & $\begin{array}{l}\text { Índice de atendimento total } \\
\text { de esgoto }\end{array}$ & IN056 & $\%$ \\
\hline & $\mathrm{O} 3$ & Índice de tratamento de água & $\begin{array}{c}(A G 007+A G 015+A G 018) / \\
(A G 006+A G 018)\end{array}$ & $\%$ \\
\hline & 04 & $\begin{array}{c}\text { Índice de tratamento de } \\
\text { esgoto }\end{array}$ & IN016 & $\%$ \\
\hline & $\mathrm{O} 5$ & $\begin{array}{l}\text { Índice de perdas na } \\
\text { distribuição }\end{array}$ & IN049 & $\%$ \\
\hline & 06 & $\begin{array}{l}\text { Consumo médio per capita } \\
\text { de água }\end{array}$ & INO22 & L/habitantes /dia \\
\hline \multirow{5}{*}{$\begin{array}{l}\text { Econômico- financeiro e } \\
\text { administrativo }\end{array}$} & E1 & $\begin{array}{l}\text { Indicador de desempenho } \\
\text { financeiro }\end{array}$ & IN012 & $\%$ \\
\hline & E2 & Índice de evasão de receitas & IN029 & $\%$ \\
\hline & E3 & $\begin{array}{l}\text { Índice de investimentos no } \\
\text { sistema de água }\end{array}$ & $\begin{array}{c}(\mathrm{FNO23}+\mathrm{FNO42}+\mathrm{FN052}) / \\
\text { FN005 }\end{array}$ & $\%$ \\
\hline & E4 & $\begin{array}{l}\text { Índice de investimentos no } \\
\text { sistema de esgoto }\end{array}$ & $\begin{array}{c}(\mathrm{FNO24}+\mathrm{FNO43}+\mathrm{FNO53}) / \\
\text { FN005 }\end{array}$ & $\%$ \\
\hline & E5 & Índice de produtividade & IN048 & $\begin{array}{l}\text { Empregados } \\
\text { /mil ligações }\end{array}$ \\
\hline \multirow{3}{*}{ Qualidade } & Q1 & Reclamações resolvidas & $\begin{array}{l}\text { QD024 } \\
\text { /QD023 }\end{array}$ & Serviços/Reclamações \\
\hline & Q2 & $\begin{array}{l}\text { Paralisação na distribuição / } \\
\text { extensão de rede de água }\end{array}$ & $\begin{array}{l}\text { QD002 } \\
\text { /AG005 }\end{array}$ & Paralisação/km \\
\hline & Q3 & $\begin{array}{l}\text { Extravasamentos de esgoto } \\
\text { por extensão de rede }\end{array}$ & IN082 & Extravasamento $/ \mathrm{km}$ \\
\hline
\end{tabular}

Fonte: SNIS (2016).

\subsection{Normalização dos critérios}

Para seguir com o desenvolvimento do método, foi necessário realizar a etapa de normalização, com a finalidade de tornar os valores dos critérios selecionados adimensionais, uma vez que seria impossível calcular e comparar critérios com unidades diferentes.

A normalização utilizou o método do redimensionamento contínuo (JUWANA et al., 2012), que classifica os valores entre 0 e 1 por meio das Eq. 1 e 2, sendo a primeira aplicada para os casos em que os critérios são preferencialmente maximizados, e a segunda para os casos em que os critérios são preferencialmente minimizados.

$S_{i}=\frac{X_{i}-X_{i n f}}{X_{\text {sup }}-X_{i n f}}$

$$
S_{i}=1-\left(\frac{X_{i}-X_{\text {inf }}}{X_{\text {sup }}-X_{\text {inf }}}\right)
$$

Onde:

$\mathrm{S}_{\mathrm{i}}=$ valor normalizado;

$X_{i}=$ valor a ser normalizado;

$\mathrm{X}_{\text {inf }}=$ limite inferior;

$\mathrm{X}_{\text {sup }}=$ limite superior.

Para definição dos limites superior e inferior, foram selecionados os valores dos critérios para as cinco regiões brasileiras, no mesmo ano de 2013 (Tabela 3). Essa determinação ocorreu para que as comparações se tornassem mais próximas de um cenário ideal, já que se esses limites ficassem restritos aos municípios da microrregião estudada, haveria resultado tendencioso na normalização, de maneira que algum dos municípios sempre receberia valor 1 e outro valor 0 . 
Tabela 3 - Limites para normalização

\begin{tabular}{|c|c|c|c|c|c|c|c|}
\hline \multirow{2}{*}{ Regiões } & \multicolumn{7}{|c|}{ Critérios } \\
\hline & 01 & 02 & 03 & 04 & 05 & 06 & E1 \\
\hline Norte & 52,40 & 6,50 & 95,00 & 78,20 & 52,80 & - & 82,34 \\
\hline Nordeste & 72,10 & 22,10 & 92,00 & 78,50 & 47,30 & - & 96,97 \\
\hline Sudeste & 91,70 & 77,30 & 99,00 & 65,40 & 33,00 & - & 114,44 \\
\hline Sul & 87,40 & 38,00 & 99,00 & 84,10 & 37,00 & - & 105,44 \\
\hline Centro-oeste & 88,20 & 42,20 & 99,00 & 91,11 & 33,20 & - & 89,14 \\
\hline Superior & 91,70 & 77,30 & 99,00 & 91,11 & 33,00 & 200,00 & 114,44 \\
\hline \multirow[t]{2}{*}{ Inferior } & 52,40 & 6,50 & 92,00 & 65,40 & 52,80 & 50,00 & 82,34 \\
\hline & E2 & E3 & E4 & E5 & Q1 & Q2 & Q3 \\
\hline Norte & 18,07 & 0,22 & 0,19 & 0,35 & 1,03 & 0,14 & 11,27 \\
\hline Nordeste & 10,31 & 0,19 & 0,08 & 0,19 & 1,22 & 0,09 & 6,09 \\
\hline Sudeste & 4,89 & 0,07 & 0,11 & 0,20 & 1,36 & 0,08 & 4,19 \\
\hline Sul & 1,39 & 0,09 & 0,12 & 0,23 & 1,10 & 0,06 & 0,74 \\
\hline Centro-oeste & 4,49 & 0,12 & 0,11 & 0,21 & 1,22 & 0,04 & 4,00 \\
\hline Superior & 1,39 & 0,22 & 0,19 & 0,35 & 1,36 & 0,04 & 0,74 \\
\hline Inferior & 18,07 & 0,09 & 0,08 & 0,19 & 1,03 & 0,14 & 11,27 \\
\hline
\end{tabular}

Neste trabalho, o método passou por uma modificação associada ao critério 06 . Devido à necessidade de um limite ótimo para o consumo médio de água, esse valor ideal é de 100 L/hab.dia, e os limites superior e inferior de $200 \mathrm{~L} / \mathrm{hab}$.dia e $50 \mathrm{~L} /$ hab.dia, respectivamente (OGATA, 2014).

Para que o valor normalizado de 06 seja mais próximo de 1 quanto mais próximo do valor ideal e mais próximo de 0 quanto mais próximo dos limites, foram utilizadas as Eq. 3 e 4, sendo a primeira aplicada nos casos do critério estar abaixo de 100 L/hab.dia, e a segunda aplicada nos casos do critério estar acima de 100 L/hab.dia.

$$
S_{i}=\frac{X_{i}-50[\mathrm{l} / \mathrm{hab} . / \mathrm{dia}]}{100-50}
$$

$$
S_{i}=1-\left(\frac{X_{i}-100[\mathrm{l} / \mathrm{hab} . / \mathrm{dia}]}{200-100}\right)
$$

Onde:

$\mathrm{S}_{\mathrm{i}}=$ valor normalizado;

$X_{i}=$ valor a ser normalizado.

Para melhor verificação das condições de normalização, a Tabela 4 apresenta a relação de eficiência e a equação utilizada de cada critério.

Tabela 4 - Relações de eficiência e equações utilizadas para normalização de cada critério

\begin{tabular}{|c|c|c|c|c|}
\hline Critério & Relação de eficiência & Equação & Critério & Relação de eficiência \\
\hline 01 & Maximizar & 1 & E2 & Minimizar \\
\hline 02 & Maximizar & 1 & E3 & Maximizar \\
\hline 03 & Maximizar & 1 & E4 & Maximizar \\
\hline 04 & Maximizar & 1 & E5 & Maximizar \\
\hline 05 & Minimizar & 2 & Q1 & Maximizar \\
\hline O6 & Limite ótimo & 3 e 4 & Q2 & Minimizar \\
\hline & Maximizar & 1 & Q3 & Minimizar \\
\hline
\end{tabular}

Fonte: Elaborada pelos autores. 


\subsection{Ponderação dos critérios}

O ELECTRE II é considerado um método não-compensatório que requer informações relativas à importância dos critérios, ou seja, pesos dos critérios (ISHIZAKA; NEMERY, 2013). Para definição desses pesos, podem ser utilizadas técnicas de cálculos ou de expressões de julgamento de valor. Assim, com a definição dos pesos, o método acaba por favorecer as ações que possuem melhor performance nos critérios mais relevantes (MORAIS; ALMEIDA, 2003).

Nessa etapa, o estudo buscou definir as ponderações de forma coerente com a realidade local, aplicando questionários com especialistas em saneamento da região. Sendo assim, responderam aos questionários oito docentes da área de saneamento dos cursos de Engenharia Civil e de Engenharia Sanitária e Ambiental da Universidade Estadual da Paraíba.

O questionário consistia na especificação dos pesos de cada critério, utilizando uma escala de 1 a 3 , em que 3 significa um critério de grande representatividade, 2 um critério de média representatividade e 1 um critério de pequena representatividade. Foi utilizado, como peso, a moda dos valores de cada critério.

A Tabela 5 apresenta os pesos indicados pelos especialistas, bem como os pesos no processo de ponderação. Também estão relacionados o percentual representativo de cada critério em sua categoria e no cenário geral.

Tabela 5 - Ponderação dos critérios

\begin{tabular}{|c|c|c|c|c|c|c|c|c|c|c|c|}
\hline \multirow{2}{*}{ Critério } & \multicolumn{9}{|c|}{ Peso atribuído pelos especialistas } & \multirow{2}{*}{$\begin{array}{c}\text { Percentual } \\
\text { para cada categoria } \\
(\%)\end{array}$} & \multirow{2}{*}{$\begin{array}{c}\text { Percentual } \\
\text { do cenário geral (\%) }\end{array}$} \\
\hline & A & B & C & D & $\mathbf{E}$ & $\mathbf{F}$ & G & $\mathbf{H}$ & Moda & & \\
\hline 01 & 3 & 3 & 3 & 3 & 3 & 3 & 3 & 3 & 3 & 17,65 & 8,57 \\
\hline 02 & 3 & 3 & 3 & 3 & 3 & 3 & 2 & 3 & 3 & 17,65 & 8,57 \\
\hline 03 & 3 & 2 & 3 & 3 & 3 & 3 & 3 & 3 & 3 & 17,65 & 8,57 \\
\hline 04 & 3 & 2 & 3 & 3 & 3 & 3 & 1 & 3 & 3 & 17,65 & 8,57 \\
\hline 05 & 3 & 1 & 3 & 3 & 3 & 3 & 2 & 2 & 3 & 17,65 & 8,57 \\
\hline 06 & 2 & 3 & 3 & 2 & 3 & 2 & 2 & 1 & 2 & 11,76 & 5,71 \\
\hline E1 & 3 & 3 & 3 & 3 & 3 & 3 & 2 & 3 & 3 & 30,00 & 8,57 \\
\hline E2 & 1 & 1 & 2 & 2 & 3 & 3 & 2 & 3 & 2 & 20,00 & 5,71 \\
\hline E3 & 2 & 2 & 3 & 2 & 3 & 2 & 2 & 2 & 2 & 20,00 & 5,71 \\
\hline E4 & 2 & 2 & 3 & 2 & 3 & 2 & 1 & 2 & 2 & 20,00 & 5,71 \\
\hline E5 & 1 & 1 & 1 & 2 & 2 & 2 & 3 & 1 & 1 & 10,00 & 2,86 \\
\hline Q1 & 1 & 3 & 3 & 2 & 2 & 3 & 2 & 3 & 3 & 37,50 & 8,57 \\
\hline Q2 & 3 & 2 & 2 & 2 & 2 & 3 & 2 & 2 & 2 & 25,00 & 5,71 \\
\hline Q3 & 3 & 1 & 2 & 3 & 3 & 3 & 2 & 2 & 3 & 37,50 & 8,57 \\
\hline
\end{tabular}

Fonte: Elaborada pelos autores.

\subsection{Matrizes de concordância, discordância e veto}

O método ELECTRE II, no seu processo de análise, resolve o problema pela ordenação, baseado em critérios verdadeiros e que utiliza os conceitos de concordância e discordância para construir as relações de sobreclassificação forte e fraca, em um conjunto de alternativas (GOMES; GOMES, 2012).
Assim foi feita a construção da matriz de concordância, que representa a vantagem de uma alternativa sobre as demais. Para a construção dessa, é realizada uma comparação par a par com cada alternativa. No caso deste trabalho, entre cada município da microrregião. $\mathrm{O}$ valor calculado de cada comparação varia entre 0 e 1 e é dado por meio da Eq. 5. 
$c_{(l, k)}=\frac{\sum_{j} W^{+}+\frac{1}{2} W^{=}}{\sum_{j} w_{j}}$

Onde:

$\mathrm{C}_{(1, \mathrm{k})}=$ grau de concordância entre as alternativas l e k;

$\mathrm{W}^{+}=$peso do critério em que a alternativa é preferível;

$\mathrm{W}^{=}=$peso do critério em que a alternativa se iguala a outra;

$W^{-}=$peso do critério em que a alternativa não é preferível;

$\mathrm{wi}_{\mathrm{i}}=$ soma do peso de todos os critérios.

Vale a pena destacar que, para o cenário geral, o grau de concordância foi a média das concordâncias calculadas separadamente nas categorias Operacional, Econômico-Financeiro e Administrativo e Qualidade, pois assim estas representariam o mesmo nível de importância.

Em seguida, foi elaborada a matriz de discordância, que mede a desvantagem de uma alternativa em relação às demais. $O$ valor de cada comparação é obtido pela Eq. 6 .

$D_{(i, j)}=\max \frac{[z(j, k)-z(i, k)]}{R}$

Onde:

$D_{(i, j)}=$ grau de discordância entre as alternativas $i$ e j em relação ao critério $k$;

$Z_{(j, k)}=$ avaliação da alternativa $\mathrm{j}$ em relação ao critério k;

$Z_{(i, k)}=$ avaliação da alternativa $\mathrm{i}$ em relação ao critério k;

$\mathrm{R}=$ maior valor superior da escala numérica (de todos os critérios).

Uma vez que as matrizes de concordância e discordância foram montadas, é possível definir a matriz de veto, que irá indicar a preferência de uma alternativa em função da outra, utilizando valores limites $p$ e q. Em que $p$ é o umbral de preferência e q é o umbral de indiferença.

Os valores de $p$ e q foram definidos com base nas classificações estabelecidas por Cunha (2003), que distingue os valores escolhidos para os dois umbrais entre as situações de preferência estrita, de preferência fraca e de indiferença (Eq. 7). Cabe ao decisor definir os limites de acordo para cada classificação.

$(p, q)\left\{\begin{array}{c}(0,9,0,2) \text { preferência fraca } \\ (0,6,0,2) \text { valores de indiferença } \\ (0,7,0,5) \text { preferência estrita }\end{array}\right.$

Assim, para o cenário e dados analisados, optouse por seguir pela situação de valores de indiferença. Contudo, após uma análise de sensibilidade foi verificado que, devido à homogeneidade das alternativas, seria necessário diminuir o nível de aceitabilidade e de discordância, definindo então os umbrais de q igual a 0,5 e p igual a 0,3. Escolhidos os valores de umbral, é necessário fazer o teste de dominância, em que os valores das matrizes são comparados de acordo com o estabelecido na Eq. 8.

$S k l=\left\{\begin{array}{c}1, \text { se } C(l, k)>p \text { e } D(i, j)<q \\ 0, \text { para outros valores }\end{array}\right.$

A partir das condições estabelecidas na Eq. 8, seguindo a proposta de Oliveira et al. (2013), constrói-se a matriz de veto de forma a deixar mais claras as condições atendidas. Essa matriz é montada de forma que quando a condição dos umbrais é satisfeita, a célula da matriz recebe o valor 1 , sobreclassificando o município em relação aos demais. Quando o valor é 0 , indica que as condições dos umbrais não foram atendidas, subclassificando o município.

A partir da matriz de veto são analisadas as relações de sobreclassificação que dizem respeito 
à existência de superação e prevalência entre as alternativas, e essas relações podem ser expressas por meio da confecção de grafos. Como exposto por Almeida (2013), nesses grafos as situações são representadas a partir de setas em que o sentido da seta representa a sobreclassificação de uma alternativa por outra e a falta de setas representa incomparabilidade entre as alternativas.

Com a interpretação do grafo consegue-se distinguir qual é a melhor e a pior alternativa dentre as possíveis, determinadas a partir da quantidade de sobreclassificação que cada alternativa possui, sendo a melhor alternativa aquela que possui o maior valor de sobreclassificação e menor valor de subclassificação, significando que aquela alternativa superou mais vezes as demais e foi superada em menor quantidade.

\section{RESULTADOS E DISCUSSÃO}

De acordo com o procedimento metodológico, com a coleta de dados são determinados os valores absolutos dos critérios, que estão expostos na Tabela 6. Em seguida, por meio do redimensionado contínuo, os valores se tornam normalizados e estão apresentados de acordo com a Tabela 7.

Tabela 6 - Valores absolutos dos critérios

\begin{tabular}{|c|c|c|c|c|c|c|c|}
\hline \multirow{2}{*}{ Municípios } & \multicolumn{7}{|c|}{ Critérios } \\
\hline & 01 & 02 & 03 & 04 & 05 & 06 & E1 \\
\hline Araruna (A) & 56,68 & 28,23 & 88,95 & 100,00 & 7,57 & 58,01 & 58,56 \\
\hline Cacimba de Dentro (CD) & 61,85 & 0,00 & 86,21 & 0,00 & 0,64 & 89,60 & 40,62 \\
\hline Casserengue (C) & 45,40 & 0,00 & 100,00 & 0,00 & 23,25 & 75,31 & 61,38 \\
\hline Dona Inês (D) & 44,26 & 0,00 & 33,08 & 0,00 & 27,36 & 63,50 & 15,94 \\
\hline Riachão (R) & 62,04 & 0,00 & 28,17 & 0,00 & 34,62 & 83,51 & 15,26 \\
\hline Solânea (S) & 73,47 & 0,00 & 62,46 & 0,00 & 6,73 & 100,80 & 44,09 \\
\hline \multirow[t]{2}{*}{ Tacima (T) } & 57,16 & 0,00 & 100,00 & 0,00 & 7,20 & 30,76 & 31,20 \\
\hline & E2 & E3 & E4 & E5 & Q1 & Q2 & Q3 \\
\hline Araruna (A) & 7,54 & 0,00 & 0,00 & 1,57 & 0,75 & 0,00 & 0,00 \\
\hline Cacimba de Dentro (CD) & 19,53 & 0,00 & 0,00 & 2,07 & 0,23 & 0,00 & 0,00 \\
\hline Casserengue (C) & 7,81 & 0,00 & 0,00 & 1,01 & 0,82 & 0,00 & 0,00 \\
\hline Dona Inês (D) & $-0,56$ & 0,00 & 0,00 & 4,67 & 0,74 & 0,00 & 0,00 \\
\hline Riachão (R) & 11,65 & 0,00 & 0,00 & 1,58 & 0,47 & 0,00 & 0,00 \\
\hline Solânea (S) & 13,92 & 1,02 & 0,00 & 2,91 & 0,47 & 0,00 & 0,00 \\
\hline Tacima (T) & $-15,23$ & 0,00 & 0,00 & 1,93 & 0,61 & 0,00 & 0,00 \\
\hline
\end{tabular}

Tabela 7 - Valores normalizados dos critérios

\begin{tabular}{|c|c|c|c|c|c|c|c|}
\hline \multirow{2}{*}{ Municípios } & \multicolumn{7}{|c|}{ Critérios } \\
\hline & 01 & 02 & 03 & 04 & 05 & 06 & E1 \\
\hline Araruna (A) & 0,11 & 0,31 & 0,00 & 1,00 & 1,00 & 0,16 & 0,00 \\
\hline Cacimba de Dentro (CD) & 0,24 & 0,00 & 0,00 & 0,00 & 1,00 & 0,79 & 0,00 \\
\hline Casserengue (C) & 0,00 & 0,00 & 1,00 & 0,00 & 1,00 & 0,51 & 0,00 \\
\hline Dona Inês (D) & 0,00 & 0,00 & 0,00 & 0,00 & 1,00 & 0,27 & 0,00 \\
\hline Riachão (R) & 0,25 & 0,00 & 0,00 & 0,00 & 0,92 & 0,67 & 0,00 \\
\hline Solânea (S) & 0,54 & 0,00 & 0,00 & 0,00 & 1,00 & 0,99 & 0,00 \\
\hline \multirow[t]{2}{*}{ Tacima (T) } & 0,12 & 0,00 & 1,00 & 0,00 & 1,00 & 0,00 & 0,00 \\
\hline & E2 & E3 & E4 & E5 & Q1 & Q2 & Q3 \\
\hline Araruna (A) & 0,63 & 0,00 & 0,00 & 1,00 & 0,00 & 1,00 & 1,00 \\
\hline Cacimba de Dentro (CD) & 0,00 & 0,00 & 0,00 & 1,00 & 0,00 & 1,00 & 1,00 \\
\hline Casserengue (C) & 0,62 & 0,00 & 0,00 & 1,00 & 0,00 & 1,00 & 1,00 \\
\hline Dona Inês (D) & 1,00 & 0,00 & 0,00 & 1,00 & 0,00 & 1,00 & 1,00 \\
\hline Riachão (R) & 0,38 & 0,00 & 0,00 & 1,00 & 0,00 & 1,00 & 1,00 \\
\hline Solânea (S) & 0,25 & 1,00 & 0,00 & 1,00 & 0,00 & 1,00 & 1,00 \\
\hline Tacima (T) & 1,00 & 0,00 & 0,00 & 1,00 & 0,00 & 1,00 & 1,00 \\
\hline
\end{tabular}

Fonte: Elaborada pelos autores. 
De posse dos valores normalizados dos critérios, foi definida a matriz de concordância para cada categoria separadamente
(Tabela 8) e em conjunto (Tabela 9), realizando a comparação de superação par a par entre os municípios.

Tabela 8 - Matriz de concordância de cada categoria

\begin{tabular}{|c|c|c|c|c|c|c|c|}
\hline \multirow[b]{2}{*}{ Municípios } & \multicolumn{7}{|c|}{ Categoria Operacional } \\
\hline & Araruna & $\begin{array}{c}\text { Cacimba de } \\
\text { Dentro }\end{array}$ & Casserengue & Dona Inês & Riachão & Solânea & Tacima \\
\hline Araruna & $x$ & 0,53 & 0,62 & 0,71 & 0,62 & 0,53 & 0,56 \\
\hline Cacimba de Dentro & 0,47 & $x$ & 0,56 & 0,65 & 0,56 & 0,35 & 0,56 \\
\hline Casserengue & 0,38 & 0,44 & $x$ & 0,65 & 0,53 & 0,44 & 0,47 \\
\hline Dona Inês & 0,29 & 0,35 & 0,35 & $x$ & 0,44 & 0,35 & 0,38 \\
\hline Riachão & 0,38 & 0,44 & 0,47 & 0,56 & $x$ & 0,26 & 0,47 \\
\hline Solânea & 0,47 & 0,65 & 0,56 & 0,65 & 0,74 & $x$ & 0,56 \\
\hline Tacima & 0,44 & 0,44 & 0,53 & 0,62 & 0,53 & 0,44 & $x$ \\
\hline \multirow[b]{2}{*}{ Municípios } & \multicolumn{7}{|c|}{ Categoria Econômico-financeiro e administrativo } \\
\hline & Araruna & $\begin{array}{c}\text { Cacimba de } \\
\text { Dentro }\end{array}$ & Casserengue & Dona Inês & Riachão & Solânea & Tacima \\
\hline Araruna & $x$ & 0,60 & 0,60 & 0,40 & 0,60 & 0,50 & 0,40 \\
\hline Cacimba de Dentro & 0,40 & $\mathrm{x}$ & 0,40 & 0,40 & 0,40 & 0,30 & 0,40 \\
\hline Casserengue & 0,40 & 0,60 & $x$ & 0,40 & 0,60 & 0,50 & 0,40 \\
\hline Dona Inês & 0,60 & 0,60 & 0,60 & $x$ & 0,60 & 0,50 & 0,50 \\
\hline Riachão & 0,40 & 0,60 & 0,40 & 0,40 & $x$ & 0,50 & 0,40 \\
\hline Solânea & 0,50 & 0,70 & 0,50 & 0,50 & 0,50 & $x$ & 0,50 \\
\hline Tacima & 0,60 & 0,60 & 0,60 & 0,50 & 0,60 & 0,50 & $x$ \\
\hline \multirow[b]{2}{*}{ Municípios } & \multicolumn{7}{|c|}{ Categoria Qualidade } \\
\hline & Araruna & $\begin{array}{c}\text { Cacimba de } \\
\text { Dentro }\end{array}$ & Casserengue & Dona Inês & Riachão & Solânea & Tacima \\
\hline Araruna & $x$ & 0,50 & 0,50 & 0,50 & 0,50 & 0,50 & 0,50 \\
\hline Cacimba de Dentro & 0,50 & $x$ & 0,50 & 0,50 & 0,50 & 0,50 & 0,50 \\
\hline Casserengue & 0,50 & 0,50 & $x$ & 0,50 & 0,50 & 0,50 & 0,50 \\
\hline Dona Inês & 0,50 & 0,50 & 0,50 & $x$ & 0,50 & 0,50 & 0,50 \\
\hline Riachão & 0,50 & 0,50 & 0,50 & 0,50 & $x$ & 0,50 & 0,50 \\
\hline Solânea & 0,50 & 0,50 & 0,50 & 0,50 & 0,50 & $x$ & 0,50 \\
\hline Tacima & 0,50 & 0,50 & 0,50 & 0,50 & 0,50 & 0,50 & $x$ \\
\hline
\end{tabular}

Fonte: Elaborada pelos autores.

Tabela 9 - Matriz de concordância de todas as categorias

\begin{tabular}{|c|c|c|c|c|c|c|c|}
\hline \multirow[b]{2}{*}{ Municípios } & \multicolumn{7}{|c|}{ Categoria Operacional } \\
\hline & Araruna & $\begin{array}{c}\text { Cacimba de } \\
\text { Dentro }\end{array}$ & Casserengue & Dona Inês & Riachão & Solânea & Tacima \\
\hline Araruna & $x$ & 0,54 & 0,57 & 0,54 & 0,57 & 0,51 & 0,49 \\
\hline Cacimba de Dentro & 0,46 & $x$ & 0,49 & 0,52 & 0,49 & 0,38 & 0,49 \\
\hline Casserengue & 0,43 & 0,51 & $x$ & 0,52 & 0,54 & 0,48 & 0,46 \\
\hline Dona Inês & 0,46 & 0,48 & 0,48 & $x$ & 0,51 & 0,45 & 0,46 \\
\hline Riachão & 0,43 & 0,51 & 0,46 & 0,49 & $x$ & 0,42 & 0,46 \\
\hline Solânea & 0,49 & 0,62 & 0,52 & 0,55 & 0,58 & $x$ & 0,52 \\
\hline Tacima & 0,51 & 0,51 & 0,54 & 0,54 & 0,54 & 0,48 & $x$ \\
\hline
\end{tabular}

Fonte: Elaborada pelos autores.

De maneira análoga ao anteriormente exposto, foi realizado o cálculo da matriz de discordância para as categorias separadamente (Tabela 10) e em conjunto (Tabela 11). No entanto, esses valores representam o quão superado foi o município numa comparação par a par. 
Tabela 10 - Matriz de discordância de cada categoria

\begin{tabular}{|c|c|c|c|c|c|c|c|}
\hline \multirow[b]{2}{*}{ Municípios } & \multicolumn{7}{|c|}{ Categoria Operacional } \\
\hline & Araruna & $\begin{array}{c}\text { Cacimba de } \\
\text { Dentro }\end{array}$ & Casserengue & Dona Inês & Riachão & Solânea & Tacima \\
\hline Araruna & $x$ & 0,63 & 1,00 & 0,11 & 0,51 & 0,83 & 1,00 \\
\hline Cacimba de Dentro & 1,00 & $x$ & 1,00 & 0,00 & 0,00 & 0,30 & 1,00 \\
\hline Casserengue & 1,00 & 0,29 & $\mathrm{x}$ & 0,00 & 0,25 & 0,54 & 0,12 \\
\hline Dona Inês & 1,00 & 0,52 & 1,00 & $x$ & 0,40 & 0,72 & 1,00 \\
\hline Riachão & 1,00 & 0,12 & 1,00 & 0,08 & $x$ & 0,32 & 1,00 \\
\hline Solânea & 1,00 & 0,00 & 1,00 & 0,00 & 0,00 & $x$ & 1,00 \\
\hline Tacima & 1,00 & 0,79 & 0,51 & 0,27 & 0,67 & 0,99 & $x$ \\
\hline \multirow[b]{2}{*}{ Municípios } & \multicolumn{7}{|c|}{ Categoria Econômico-financeiro e administrativo } \\
\hline & Araruna & $\begin{array}{c}\text { Cacimba de } \\
\text { Dentro }\end{array}$ & Casserengue & Dona Inês & Riachão & Solânea & Tacima \\
\hline Araruna & $x$ & 0,00 & 0,00 & 0,37 & 0,00 & 1,00 & 0,37 \\
\hline Cacimba de Dentro & 1,00 & $\mathrm{x}$ & 0,62 & 1,00 & 0,38 & 1,00 & 1,00 \\
\hline Casserengue & 0,02 & 0,00 & $x$ & 0,38 & 0,00 & 1,00 & 0,38 \\
\hline Dona Inês & 0,00 & 0,00 & 0,00 & $x$ & 0,00 & 1,00 & 0,00 \\
\hline Riachão & 0,25 & 0,00 & 0,23 & 0,62 & $x$ & 1,00 & 0,62 \\
\hline Solânea & 0,38 & 0,00 & 0,37 & 0,75 & 0,14 & $x$ & 0,75 \\
\hline Tacima & 0,00 & 0,00 & 0,00 & 0,00 & 0,00 & 1,00 & $x$ \\
\hline \multirow[b]{2}{*}{ Municípios } & \multicolumn{7}{|c|}{ Categoria Qualidade } \\
\hline & Araruna & $\begin{array}{c}\text { Cacimba de } \\
\text { Dentro }\end{array}$ & Casserengue & Dona Inês & Riachão & Solânea & Tacima \\
\hline Araruna & $x$ & 0,00 & 0,00 & 0,00 & 0,00 & 0,00 & 0,00 \\
\hline Cacimba de Dentro & 0,00 & $x$ & 0,00 & 0,00 & 0,00 & 0,00 & 0,00 \\
\hline Casserengue & 0,00 & 0,00 & $x$ & 0,00 & 0,00 & 0,00 & 0,00 \\
\hline Dona Inês & 0,00 & 0,00 & 0,00 & $x$ & 0,00 & 0,00 & 0,00 \\
\hline Riachão & 0,00 & 0,00 & 0,00 & 0,00 & $x$ & 0,00 & 0,00 \\
\hline Solânea & 0,00 & 0,00 & 0,00 & 0,00 & 0,00 & $\mathrm{x}$ & 0,00 \\
\hline Tacima & 0,00 & 0,00 & 0,00 & 0,00 & 0,00 & 0,00 & $x$ \\
\hline
\end{tabular}

Fonte: Elaborado pelos autores.

Em seguida, utilizando os umbrais selecionados - $p$ igual a 0,5 e q igual a 0,3, nas matrizes de concordância e discordância respectivamente -, obtiveram-se as matrizes de veto para as categorias separadamente (Tabela 12) e em conjunto

(Tabela 13).

Tabela 11 - Matriz de discordância da todas as categorias

\begin{tabular}{|c|c|c|c|c|c|c|c|}
\hline Municípios & Araruna & $\begin{array}{c}\text { Cacimba de } \\
\text { Dentro }\end{array}$ & Casserengue & Dona Inês & Riachão & Solânea & Tacima \\
\hline Araruna & $x$ & 0,63 & 1,00 & 0,37 & 0,51 & 1,00 & 1,00 \\
\hline Cacimba de Dentro & 1,00 & $\mathrm{x}$ & 1,00 & 1,00 & 0,38 & 1,00 & 1,00 \\
\hline Casserengue & 1,00 & 0,29 & $x$ & 0,38 & 0,25 & 1,00 & 0,38 \\
\hline Dona Inês & 1,00 & 0,52 & 1,00 & $x$ & 0,40 & 1,00 & 1,00 \\
\hline Riachão & 1,00 & 0,12 & 1,00 & 0,62 & $x$ & 1,00 & 1,00 \\
\hline Solânea & 1,00 & 0,00 & 0,00 & 0,75 & 0,14 & $x$ & 1,00 \\
\hline Tacima & 1,00 & 0,79 & 0,51 & 0,27 & 0,67 & 1,00 & $x$ \\
\hline
\end{tabular}


Tabela 12 - Matriz de veto de cada categoria

\begin{tabular}{|c|c|c|c|c|c|c|c|}
\hline \multirow[b]{2}{*}{ Municípios } & \multicolumn{7}{|c|}{ Categoria Operacional } \\
\hline & Araruna & $\begin{array}{c}\text { Cacimba de } \\
\text { Dentro }\end{array}$ & Casserengue & Dona Inês & Riachão & Solânea & Tacima \\
\hline Araruna & $x$ & 0 & 0 & 1 & 0 & 0 & 0 \\
\hline Cacimba de Dentro & 0 & $x$ & 0 & 1 & 1 & 0 & 0 \\
\hline Casserengue & 0 & 0 & $x$ & 1 & 1 & 0 & 0 \\
\hline Dona Inês & 0 & 0 & 0 & $x$ & 0 & 0 & 0 \\
\hline Riachão & 0 & 0 & 0 & 1 & $x$ & 0 & 0 \\
\hline Solânea & 0 & 1 & 0 & 1 & 1 & $x$ & 0 \\
\hline Tacima & 0 & 0 & 0 & 1 & 0 & 0 & $x$ \\
\hline \multirow[b]{2}{*}{ Municípios } & \multicolumn{7}{|c|}{ Categoria Econômico-financeiro e administrativo } \\
\hline & Araruna & $\begin{array}{c}\text { Cacimba de } \\
\text { Dentro }\end{array}$ & Casserengue & Dona Inês & Riachão & Solânea & Tacima \\
\hline Araruna & $x$ & 1 & 1 & 0 & 1 & 0 & 0 \\
\hline Cacimba de Dentro & 0 & $x$ & 0 & 0 & 0 & 0 & 0 \\
\hline Casserengue & 0 & 1 & $x$ & 0 & 1 & 0 & 0 \\
\hline Dona Inês & 1 & 1 & 1 & $x$ & 1 & 0 & 0 \\
\hline Riachão & 0 & 1 & 0 & 0 & $x$ & 0 & 0 \\
\hline Solânea & 0 & 1 & 0 & 0 & 0 & $x$ & 0 \\
\hline Tacima & 1 & 1 & 1 & 0 & 1 & 0 & $x$ \\
\hline \multirow[b]{2}{*}{ Municípios } & \multicolumn{7}{|c|}{ Categoria Qualidade } \\
\hline & Araruna & $\begin{array}{c}\text { Cacimba de } \\
\text { Dentro }\end{array}$ & Casserengue & Dona Inês & Riachão & Solânea & Tacima \\
\hline Araruna & $x$ & 0 & 0 & 0 & 0 & 0 & 0 \\
\hline Cacimba de Dentro & 0 & $x$ & 0 & 0 & 0 & 0 & 0 \\
\hline Casserengue & 0 & 0 & $x$ & 0 & 0 & 0 & 0 \\
\hline Dona Inês & 0 & 0 & 0 & $x$ & 0 & 0 & 0 \\
\hline Riachão & 0 & 0 & 0 & 0 & $x$ & 0 & 0 \\
\hline Solânea & 0 & 0 & 0 & 0 & 0 & $x$ & 0 \\
\hline Tacima & 0 & 0 & 0 & 0 & 0 & 0 & $x$ \\
\hline
\end{tabular}

Fonte: Elaborada pelos autores.

Tabela 13 - Matriz de veto de todas as categorias

\begin{tabular}{|c|c|c|c|c|c|c|c|}
\hline Municípios & Araruna & $\begin{array}{c}\text { Cacimba de } \\
\text { Dentro }\end{array}$ & Casserengue & Dona Inês & Riachão \\
\hline Araruna & $\mathrm{x}$ & 0 & 0 & 0 & 0 \\
\hline Cacimba de Dentro & 0 & $\mathrm{x}$ & 0 & 0 & 0 \\
\hline Casserengue & 0 & 1 & $\mathrm{x}$ & 0 & 1 \\
\hline Dona Inês & 0 & 0 & 0 & $\mathrm{x}$ & 0 \\
\hline Riachão & 0 & 1 & 0 & 0 & 0 \\
\hline Solânea & 0 & 1 & 1 & 0 & 0 \\
\hline Tacima & 0 & 0 & 0 & 1 & 0 \\
\hline
\end{tabular}

Fonte: Elaborada pelos autores.

A partir da matriz de veto, é possível exibir os resultados na forma do grafo de sobreclassificação, que é uma maneira visualmente mais inteligível, capaz de indicar quais municípios apresentaram melhor desempenho em relação aos demais. Essa representação ocorre por meio de setas em que, quanto mais setas saem da alternativa, maior sua sobreclassificação, e quanto mais chegam, maior a subclassificação, de maneira que o município com maior sobreclassificação e menor subclassificação é o que possui melhor desempenho.

Sendo assim, mantendo a lógica metodológica, foi criado o grafo de sobreclassificação para as categorias separadamente e em conjunto. Na Fig. 2, por exemplo, é apresentado o grafo e matriz de sobreclassificação para a categoria Operacional, mostrando que o município de Solânea apresentou melhor desempenho, e Dona Inês, o pior. 


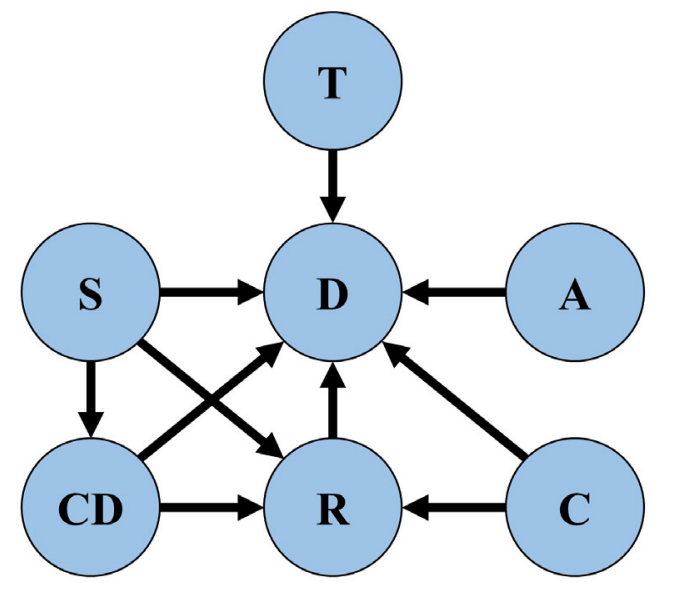

\begin{tabular}{|c|c|c|c|}
\hline Municípios & $\begin{array}{c}\text { Sobre- } \\
\text { classificação }\end{array}$ & $\begin{array}{c}\text { Sub- } \\
\text { classificação }\end{array}$ & Ranque \\
\hline Araruna & 1 & 0 & $1^{\circ}$ Solânea \\
\hline $\begin{array}{c}\text { Cacimba de } \\
\text { Dentro }\end{array}$ & 2 & 1 & $2^{\circ}$ Casserengue \\
\hline Casserengue & 2 & 0 & $\begin{array}{c}3^{\circ} \text { Cacimba } \\
\text { de Dentro }\end{array}$ \\
\hline Dona Inês & 0 & 6 & $4^{\circ}$ Araruna \\
\hline Riachão & 1 & 3 & Tacima \\
\hline Solânea & 3 & 0 & $5^{\circ}$ Riachão \\
\hline Tacima & 1 & 0 & $6^{\circ}$ Dona Inês \\
\hline
\end{tabular}

Figura 2 - Grafo e matriz de sobreclassificação para a categoria Operacional Fonte: Elaborada pelos autores.

Por sua vez, a Fig. 3 apresenta o grafo e a matriz de sobreclassificação para a categoria Econômico-Financeiro e Administrativo, em que os muni- cípios de Dona Inês e Tacima se destacaram positivamente e o município de Cacimba de Dentro se destacou negativamente.

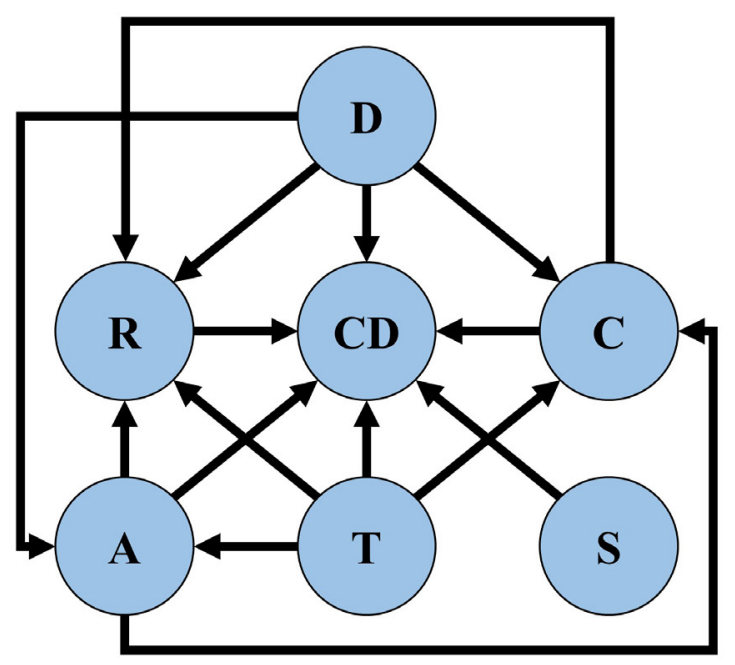

\begin{tabular}{|c|c|c|c|}
\hline Municípios & $\begin{array}{c}\text { Sobre- } \\
\text { classificação }\end{array}$ & $\begin{array}{c}\text { Sub- } \\
\text { classificação }\end{array}$ & Ranque \\
\hline Araruna & 3 & 2 & $1^{\circ}$ Dona Inês \\
\hline $\begin{array}{c}\text { Cacimba de } \\
\text { Dentro }\end{array}$ & 0 & 6 & $\begin{array}{c}\text { Tacima } \\
2^{\mathrm{a}} \text { Araruna }\end{array}$ \\
\hline Casserengue & 2 & 3 & $3^{\circ}$ Solânea \\
\hline Dona Inês & 4 & 0 & $4^{\circ}$ Casserengue \\
\hline Riachão & 1 & 4 & $5^{\circ}$ Riachão \\
\hline Solânea & 1 & 0 & $6^{\circ}$ Cacimba \\
\hline Tacima & 4 & 0 & de Dentro \\
\hline
\end{tabular}

Figura 3 - Grafo e matriz de sobreclassificação para a categoria Econômico-Financeiro e Administrativo Fonte: Elaborada pelos autores.

Quanto à Fig. 4, que apresenta o grafo e matriz de sobreclassificação para a categoria Qualidade, foi possível verificar que todos os municípios se encontram em condição muito semelhante, não possuindo relação de dominância. 


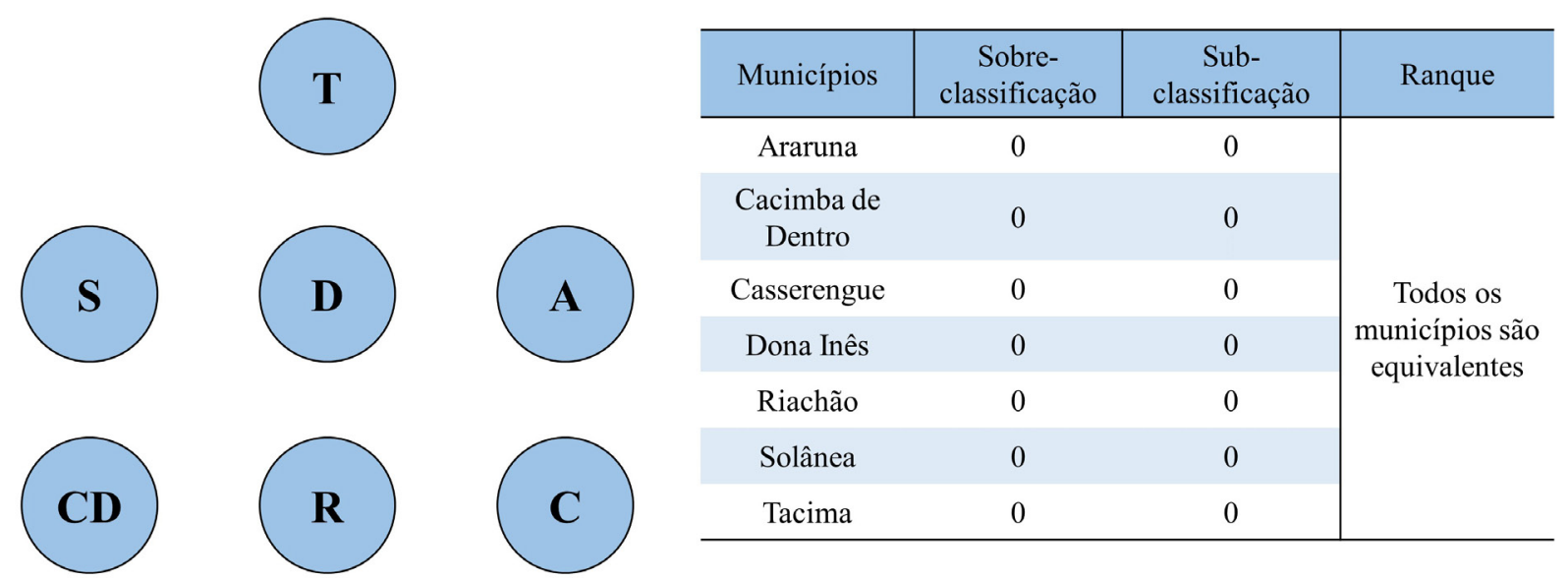

Figura 4 - Grafo e matriz de sobreclassificação para a categoria Qualidade Fonte: Elaborada pelos autores.

Em conclusão, a Fig. 5 apresenta o grafo e a matriz de sobreclassificação analisando todos os critérios juntos. Com base nisso, Solânea apresentou melhor condição no cenário geral e Cacimba de Dentro a pior, e o município de Araruna não apresentou relação de dominância com nenhum outro município.
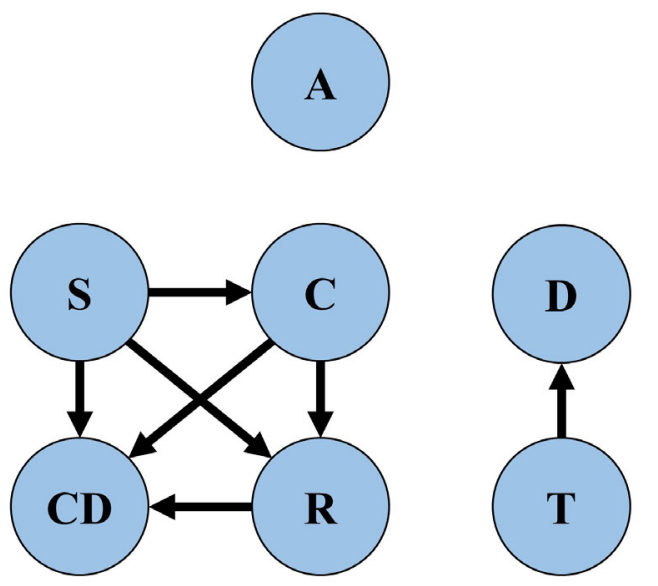

\begin{tabular}{c|c|c|c}
\hline Municípios & $\begin{array}{c}\text { Sobre- } \\
\text { classificação }\end{array}$ & $\begin{array}{c}\text { Sub- } \\
\text { classificação }\end{array}$ & Ranque \\
\hline $\begin{array}{c}\text { Araruna } \\
\text { Cacimba de } \\
\text { Dentro }\end{array}$ & 0 & 0 & $1^{\circ}$ Solânea \\
Casserengue & 2 & 3 & $2^{\circ}$ Casserengue \\
Dona Inês & 0 & 1 & $3^{\circ}$ Tacima \\
Riachão & 1 & 1 & $4^{\circ}$ Riachão \\
Solânea & 3 & 2 & $5^{\circ}$ Dona Inês \\
Tacima & 1 & 0 & $6^{\circ}$ Cacimba \\
\hline
\end{tabular}

Figura 5 - Grafo e matriz de sobreclassificação para todas as categorias Fonte: Elaborada pelos autores.

\section{DISCUSSÃO}

Ao analisar os resultados das Tabelas 6 e 7, em que estão os valores absolutos e normalizados dos critérios coletados do SNIS, antes de tudo, é importante destacar que apesar de o SNIS ser a maior e mais importante base de dados do saneamento básico brasileiro (CARNEIRO et al.;
2018), ainda possui muitas limitações quanto à disponibilidade e veracidade das informações, pois o sistema é preenchido pelos próprios prestadores de serviço, que por vezes falham ou equivocam-se no processo (COSTA et. al., 2013; CERI, 2018). 
Especificamente em relação aos critérios da categoria Operacional, é possível verificar a fragilidade dos municípios na infraestrutura de abastecimento de água, a qual é comprovada por meio da baixa cobertura da prestação do serviço (01), em que menos de $50 \%$ da população de Casserengue e Dona Inês possuem acesso. Em complemento, o tratamento de água (03) também é falho, pois apenas os municípios de Casserengue e Tacima tratam $100 \%$ da água distribuída.

Outro aspecto interessante são as perdas na distribuição (05), que mesmo considerando medições de vazão (macro e micro) e respeitando os limites de cada setor, estão mantidas virtualmente baixas, o que leva a relacionar esses baixos valores à escassez de água que a região vem passando no período de 2012-2016 (MEDEIROS E BRITO, 2017) - comprovada pelos baixos valores de consumo per capita (06), com destaque para o município de Tacima com valores menores que o recomendado pela Organização Mundial da Saúde (2003) - com as perdas reduzidas pela baixa vazão e pressão no sistema causadas pelo racionamento e não por medidas tomadas no sentido de monitorar e solucionar as falhas (ABES, 2015).

A infraestrutura de esgotamento sanitário também é frágil: apenas o município de Araruna indicou a presença de coleta (O2) e tratamento dos efluentes (04). No entanto, esse resultado pode ser questionável, pois o Censo 2010 (IBGE, 2011) indicou a presença de serviço de esgotamento nos demais municípios, podendo o serviço ser municipalizado e não relatado ao SNIS.

No que se refere à categoria Econômico-Financeiro e Administrativo, apesar de haver quantidade suficiente de funcionários para manter os sistemas de abastecimento de água e esgotamento sanitário (E5), apenas o município de Solânea recebeu investimento no ano de 2013. A manutenção econômico-financeira dos sistemas é vulnerável, pois os custos são altos em relação à receita (E1) e há altos índices de endividamento dos usuários (E2) com destaque para Cacimba de Dentro, que alcança quase $20 \%$ de endividamento.

Explorando os critérios da categoria Qualidade, o mais importante é destacar a homogeneidade entre os municípios, em que todos possuem baixos índices de resolução de reclamações (Q1), paralisações do abastecimento de água (Q2) e extravasão da rede de esgoto (Q3). Contudo, o critério Q2 deve possuir algum erro no preenchimento, pois é natural que haja paralisações no sistema de abastecimento, nem que seja para realizar manutenção (MINISTÉRIO DAS CIDADES, 2008).

Ao analisar a relação de dominância entre os municípios, operacionalmente, Solânea está em melhor condição, pois apesar de não possuir sistema de esgotamento sanitário registrado no SNIS, possui melhor cobertura do serviço de abastecimento de água em quantidade suficiente. Enquanto isso, Dona Inês está em pior situação, pois não possui nenhum dos serviços prestados em boas condições. Vale a pena destacar que no município de Araruna, apesar de ser o único a possuir sistema de esgotamento sanitário, as condições do fornecimento de água associado a cobertura e quantidade não estão adequadas.

Essa situação denota uma necessidade de investimento prioritário na operacionalidade dos sistemas de abastecimento de água e esgotamento sanitário no município de Dona Inês, pois a quantidade e a qualidade da água fornecida não estão adequadas e a cobertura ainda é muito baixa.

Quanto à categoria Econômico-Financeiro e Administrativo, o critério mais significativo foi o endividamento dos usuários. Os destaques positivos foram os municípios de Dona Inês e Tacima, garantindo uma arrecadação para os sistemas, e o destaque negativo foi Cacimba de Dentro, com o pior endividamento da microrregião. 0 município de Solânea, apesar de ter sido o único a receber investimentos, possui endividamento que ul- 
trapassa os $10 \%$, ficando na $3^{\text {a }}$ colocação, após o município de Araruna.

Assim, a prioridade para investimentos na meIhoria da condição econômico-financeira é para o município de Cacimba de Dentro, a fim de tornar os sistemas de abastecimento de água e 16 esgotamento sanitário autossuficientes, tornando-os dependentes apenas das arrecadações dos usuários para se manter, assim como indicado por FUNASA (2014).

Devido à homogeneidade da qualidade dos serviços prestados, não há dominância entre os municípios e, consequentemente, preferência no investimento nessa categoria.

Quando se analisam as três categorias em conjunto, verifica-se que Solânea está em melhor condição que os demais, principalmente devido a sua condição operacional e os investimentos recebidos no sistema de abastecimento de água. Enquanto isso, Cacimba de Dentro, devido a sua fragilidade operacional e econômico-financeira, é prioridade para investimento no cenário geral.

$\mathrm{Na}$ análise com todas as categorias, apenas o município de Araruna não apresentou nenhuma relação de dominância. Portanto, pode ser escoIhido em detrimento de qualquer outro município no momento de receber algum investimento.

Assim, é possível verificar a utilidade da análise multicriterial em indicar quais as prioridades em relação ao local e às categorias necessitam de atenção (CUNHA, 2003; COSTA, 2015; OLIVEIRA, 2016; ARAÚJO e AMARAL, 2016; GOMES e GOMES, 2012; LONGARAY,2016). Dessa maneira, é possível auxiliar a tomada de decisão, aumentando as chances de uma escolha acertada sobre onde investir os recursos limitados, por meio do uso de vários critérios (DE PAULA, 2013), especialmente útil diante da complexidade e da fragilidade dos sistemas de abastecimento de água e esgotamento sanitário das cidades de pequeno porte do país.
Um aspecto importante a se discutir é a análise de sensibilidade realizada, que identificou a necessidade de modificação dos valores dos umbrais. Mesmo com a recomendação de Cunha (2003) em adotar p igual a 0,6 e q igual a 0,2, não era possível fazer uma classificação adequada devido à homogeneidade dos sistemas de saneamento estudados, pois nessas condições haveria pouca relação de dominância, em que, por exemplo, para o cenário geral apenas os municípios de Solânea e Riachão possuiriam relação de dominância. Portanto, a indicação de Araújo e Amaral (2016), Infante et al. (2014) e Gomes e Costa (2015) sobre a necessidade de realização de análise de sensibilidade foi pertinente, uma vez que proporcionou alcançar classificação entre os municípios ao utilizar umbrais menos distantes entre si.

\section{CONCLUSÃO}

Por meio da análise multicriterial proposta para os critérios selecionados no escopo dos indicadores do SNIS foi possível orientar a tomada de decisão para ações prioritárias no local e categorias adequadas. Assim, para a categoria Operacional é prioritário o investimento em Dona Inês, para a categoria Econômico-Financeiro e Administrativo a prioridade é para Cacimba de Dentro, assim como para o cenário geral.

Para avaliação da robustez do método proposto neste trabalho, seria interessante a aplicação dos critérios em outras localidades brasileiras, inclusive em municípios de médio e grande porte.

Além disso, outros métodos multicriteriais podem ser testados a fim de verificar a sensibilidade dos resultados a outras abordagens matemáticas.

Ao utilizar essa metodologia, em casos práticos, aconselha-se que além dos critérios técnicos aqui relacionados, critérios de outras naturezas, como índices de desenvolvimento humano, índice de mortalidade infantil, questões políticas, 
entre outros índices disponíveis que possam ser correlacionados a qualidade dos sistemas, sejam incorporados à análise.

\section{CONTRIBUIÇÃO DOS AUTORES}

Conceitualização: Ogata IS; Levantamento bibliográfico: Gomes BA; Redação do manuscrito:Claudino CMA; Análise dos Resultados: Claudino CMA e Ogata IS; Revisão: Ogata IS e Sena TS.

\section{REFERÊNCIAS}

ALEGRE, H.; BAPTISTA, J. M.; CABRERA JUNIOR, E.; CUBILLO, F.; DUARTE, P.; HIRNER, W.; MERKEL, W.; PARENA, R. Performance indicators for water supply services. 2. ed. Londres, 2006. https:// doi.org/10.2166/9781780405292

ALENCAR FILHO, F. M.; ABREU, L. M. Metodologia alternativa para avaliação de desempenho de companhias de saneamento básico: aplicação da análise fatorial. Planejamento e políticas públicas, Brasília, n. 28, 2005.

ALMEIDA, A. T. Processo de decisão nas organizações: construindo modelos de decisão multicritério. São Paulo: Atlas, 2013.

ARAUJO, J. J.; AMARAL, T. M. Aplicação do método ELECTRE I para problemas de seleção envolvendo projetos de desenvolvimento de software livre. Gestão da Produção, Operações e Sistemas, Bauru, Ano 11, n. 2, p. 121-137, 2016. https://doi.org/10.15675/ gepros.v11i2.1425

ATAÍDE, G. V. T. L.; BORJA, P. C. Justiça social e ambiental em saneamento básico: um olhar sobre experiências de planejamento municipais. Ambiente e Sociedade, São Paulo, v. 20, n. 3, 2017. https://doi.org/10.1590/1809-4422ASOC74R1V2032017

BRASIL. Lei no 11.445, de 5 de Janeiro de 2007. Estabelece diretrizes nacionais para o saneamento básico; altera as Leis nos 6.766, de 19 de dezembro de 1979, 8.036, de 11 de maio de 1990, 8.666, de 21 de junho de 1993, 8.987, de 13 de fevereiro de 1995; revoga a Lei no 6.528, de 11 de maio de 1978; e dá outras providências. Brasília: Casa Civil, 2007.

BRASIL. Lei no 10.257, de 10 de Julho de 2001.Regulamenta os arts. 182 e 183 da Constituição Federal, estabelece diretrizes gerais da política urbana e dá outras providências. Brasília: Casa Civil, 2001.

CAMPOS, V. R.; CAZARINI, E. W. Indicadores para a avaliação de projetos de saneamento. Revista Ibero-Americana de Ciências Ambientais, Aracaju, v. 8, p. 136-150, 2017. https://doi. org/10.6008/SPC2179-6858.2017.003.0013
CARNEIRO, M. C. M. O.; AMARAL, D. S.; SANTOS, L. F. M.; GOMES JUNIOR, M. M. A.; PINHEIRO, T. M. A. gestão do saneamento no Brasil e sua relação com a gestão de recursos hídricos. INOVAE, São Paulo, v. 6, p. 100-116, 2018.

CARVALHO, B. E.; MARQ্UES, R. C. NETTO, O. C. Rethinking Brasília's water services: 'new targets' using the regulatory impact assessment (RIA) tool. Journal of Water Sanitation and Hygiene for Development, Londres, v. 9, p. 7-18, 2019. https://doi. org/10.2166/washdev.2019.088

CECCONI, P.; FRANCESCHINI, F.; GALETTO, M. The conceptual link between measurements, evaluations, preferences and indicators, according the representational theory. European Journal of Operational Research, v. 179, p. 174-185, 2007. https://doi. org/10.1016/j.ejor.2006.03.018

CONFEDERAÇÃO NACIONAL DAS INDÚSTRIAS - CNI. Oportunidades para a privatização da infraestrutura o que fazer e como fazer. Brasília: CNI, 2017.

COSTA, R. N. P.; PINHEIRO, E. M. O cenário do saneamento básico no Brasil. Revista Educação Ambiental em Ação, Novo Hamburgo, n. 66, 2018. https://doi.org/10.35699/2316-770X.2013.2704

CUNHA, M. J. B. Aplicação da metodologia ELECTRE I de apoio da decisão multicritério na priorização de transporte de mercadoria. In: XXIII Enc. Nac. de Eng. de Prod., Ouro Preto, 2003. Anais... Belém: ENEGEP, 2003.

DANTAS, F. A.; LEONETI, A. B.; OLIVEIRA, S. V. W. B.; OLIVEIRA, M. M. B. Uma análise da situação do saneamento no Brasil. FACEF Pesquisa: Desenvolvimento e Gestão, Franca, v.15, n. 3, p.272-284, 2012.

DUTRA, V. A. B.; GONÇALVES, P. V. S., CAMPOS, M. V. A.; TAVARES, P. A.; BELTRÃO, N. E. S. Saneamento em áreas urbanas na Amazônia: aplicação do sistema de indicadores PEIR. Rev. Gest. Sust. Ambient., Florianópolis, v. 7, n. 2, p. 652-671, 2018. https://doi. org/10.19177/rgsa.v7e22018652-671

GOMES, C. F. S.; COSTA, H. G. Aplicação de métodos multicritério ao problema de escolha de modelos de pagamento eletrônico por cartão de crédito. Produção, São Paulo, v. 25, n. 1, 2015. https:// doi.org/10.1590/S0103-65132013005000068

GOMES, L. F. A. M.; GOMES, C. F. S. Tomada de decisão gerencial: enfoque multicritério. 4. ed. São Paulo: Atlas, 2012.

GOVINDAN, K; JEPSEN, M. ELECTRE: A comprehensive literature review on methodologies and applications. European Journal of Operation Research, Amsterdam, n. 1, p.1-29, 2014. https://doi. org/10.1016/j.ejor.2015.07.019

GRISOTTO, L. E. G.; PEREIRA, C. A. O.; BITTENCOURT, A. G.; MACHADO, R. D. Geoestatística e avaliação multicriterial no processo de planejamento e desenvolvimento local e regional do estado de São Paulo. Paranoá: Cadernos de Arquitetura e Urbanismo, Brasília, v. 6, n. 6, 2012. https://doi.org/10.18830/issn.1679-0944. n6.2012.12284 
INFANTE, C. E. D. C.; MENDONÇA, F. M.; VALLE, R. A. B. Análise de robustez com o método Electre III: o caso da região de Campo das Vertentes em Minas Gerais. Gest. Prod., São Carlos, v. 21, n. 2, p. 245-255, 2014. https://doi.org/10.1590/0104-530X958

INSTITUTO BRASILEIRO DE GEOGRAFIA E ESTATÍSTICA - IBGE. Pesquisa Nacional de Saneamento Básico 2008. Rio de Janeiro: Ministério do Planejamento, Orçamento e Gestão, Ministério das Cidades, 2010.

INSTITUTO BRASILEIRO DE GEOGRAFIA E ESTATÍSTICA - IBGE. Censo Demográfico 2010. Características da população e dos domicílios, resultados do universo. Rio de Janeiro: Ministério do Planejamento, Orçamento e Gestão, 2011.

INSTITUTO BRASILEIRO DE GEOGRAFIA E ESTATÍSTICA - IBGE. Estimativa da população 2018. Rio de Janeiro: Ministério do Planejamento, Orçamento e Gestão, Ministério das Cidades, 2018.

INSTITUTO DE PESQUISA ECONÔMICA APLICADA - IPEA. A redução das desigualdades e seus desafios. Brasília: IPEA, 2010.

ISHIZAKA, A; NEMERY, P. Multi-Criteria Decision Analysis: Methods and Softwares. 1 ed. Nova Jersey, 2013.

JUWANA, I.; MUTTIL, N.; PERERA, B. J. C. Indicator-based water sustainability - A review. Science of the Total Environment, Amsterdam, v. 438, p. 357-371, Set. 2012. https://doi.org/10.1016/j. scitotenv.2012.08.093

LONGARAY, A. A.; MUNHOZ, P.; QUADRO, R. C.; TONDOLO, V. A. G. Análise multicritério de decisão e sua aplicação na gestão da saúde: uma proposta de revisão sistemática da literatura. Exacta - EP, São Paulo, v. 14, n. 4, p. 609-618, 2016. https://doi.org/10.5585/ exactaep.v14n 4.6490

MENDES, T. M.; BARCELLOS, C. A dimensão territorial do esgotamento sanitário: o caso do Recreio dos Bandeirantes, Rio de Janeiro, Brasil. Ciênc. saúde colet., Rio de Janeiro, v. 23, n. 2, 2018. https://doi.org/10.1590/1413-81232018232.27732015

MORAIS, D. C.; ALMEIDA, A. T. Aplicação do ELECTRE II no gerenciamento de sistemas de abastecimento de água para redução de perdas. In: XXIII Enc. Nac. de Eng. de Prod. Ouro Preto, 2003, Anais... Ouro Preto: ENEGEP, 2003.

MOTA, J. J. P.; SOUSA, C. D. S. S. Saneamento básico e seu reflexo nas condições socioambientais da zona rural do baixo Munim (Maranhão). Caminhos de Geografia Uberlândia, Uberlândia, v. 16, n. 54, p. 140-160, 2015. http://www.seer.ufu.br/index.php/ caminhosdegeografia/

NAHAS, M. I. P.; MOURA, A. S. A.; CARVALHO, R. C.; HELLER, L. Desigualdade e discriminação no acesso à água e ao esgotamento sanitário na Região Metropolitana de Belo Horizonte, Minas Gerais,
Brasil. Cad. Saúde Pública; Rio de Janeiro, v. 35, n. 4, 2019. https:// doi.org/10.1590/0102-311X00100818

NIRAZAWA, A. N.; OLIVEIRA, S. V. W. B. Indicadores de saneamento: uma análise de variáveis para elaboração de indicadores municipais. Rev. Adm. Pública, v.52, n. 4, Rio de Janeiro, 2018. https:// doi.org/10.1590/0034-7612168118

OGATA, I. S. Desenvolvimento do índice de pobreza hídrica para a bacia hidrográfica do Rio Paraíba. Campina Grande: UFCG, 2014. Dissertação (Mestrado), Universidade Federal de Campina Grande, 2014

OLIVEIRA, M; MELO, E; MOSER, D; AMARO, R. Apoio a decisão em sistemas de produção: um estudo de caso na construção naval. In: XXXIII Enc. Nac. de Eng. de Prod., 2013, Salvador. Anais... Salvador: ENEGEP, 2013.

ORGANIZAÇÃO MUNDIAL DA SAÚDE. Domestic Water Quantity, Service Level and Health. Genebra: OMS, 2003.

PAIVA, R. F. P. S.; SOUZA, M. F. P. Associação entre condições socioeconômicas, sanitárias e de atenção básica e a morbidade hospitalar por doenças de veiculação hídrica no Brasil. Cad. Saúde Pública, Rio de Janeiro, v. 34, n. 1, 2018. https://doi.org/10.1590/ 0102-311X00017316

PINHEIRO, T. F.; SILVA, T. A. R.; PESTANA, M. S. V.; LIMA, R. M. Condições de saneamento do bairro Ururaí em Campos dos Goytacazes, estado do Rio de Janeiro. Vértices, Campos dos Goytacazes, v. 19, n. 3, p. 139-170, 2017. https://doi.org/10.19180/1809-2667. v19n32017p139-170

QUEIROZ, L. R.; OLIVEIRA, J. H. J.; CLEMENTE, C. M. S.; PEREIRA, D. M. Avaliação do saneamento básico no município de Guanambi e seus limítrofes. Revista Desenvolvimento Social, Montes Claros, n. 24, p. $63-77,2018$

SISTEMA NACIONAL DE INFORMAÇÕES SOBRE SANEAMENTO SNIS. Diagnóstico dos Serviços de Água e Esgoto. Brasília: SNIS, 2016.

SOUSA, E.; RAMOS, G. O.; JÚNIOR, J. S. S.; BELTRÃO, N. E. S. Panorama situacional do serviço de esgotamento sanitário e sua relação com doenças de veiculação hídrica na região metropolitana de Belém - Pará. Rev. Gest. Sust. Ambient., Florianópolis, v. 7, n. 3, p.487- 503, 2018.

TELES, M. M. L. Qualidade técnica e eficiência financeira do setor de saneamento básico do município de acauã (PI). Revista Científica Multidisciplinar Núcleo do Conhecimento, São Paulo, v. 5, p. 58-65, 2019. https://doi.org/10.32749/nucleodoconhecimento. com.br/meio-ambiente/setor-de-saneamento

TOMÉ, L. M. Saneamento básico: situação atual e perspectivas. Caderno Setorial ETENE, Fortaleza, ano 3, n 37; 2018. 